\title{
Self-Healing Effect by Zinc Phosphate and Calcium Silicate Included in Organic-Inorganic Composite Coating on 55\% Al-Zn Coated Steel Sheet*1
}

\author{
Akira Matsuzaki ${ }^{1}$, Masayasu Nagoshi ${ }^{1}$, Hisato Noro ${ }^{1}$, Masaaki Yamashita ${ }^{1, * 2}$ and Nobuyoshi Hara ${ }^{2}$ \\ ${ }^{1}$ Steel Research Laboratory, JFE Steel Corporation, Kawasaki 210-0855, Japan \\ ${ }^{2}$ Department of Materials Science, Graduate School of Engineering, Tohoku University, Sendai 980-8579, Japan
}

\begin{abstract}
Improved corrosion resistance of steel sheets plated with zinciferous metal, and particularly 55\% Al-Zn alloy coated steel sheets, has become necessary in recent years. However, $55 \% \mathrm{Al}-\mathrm{Zn}$ alloy coated steel sheets are susceptible to surface cracks during forming due to the hardness of the metallic coating. This research examined various non-chromate corrosion-preventive compounds for organic-inorganic composite coatings and found that a composite coating containing a mixture of $\mathrm{Zn}_{3}\left(\mathrm{PO}_{4}\right)_{2}$ and CaSiO 3 provided the highest corrosion resistance among all the additives tested. The corrosion mechanism was investigated by post-test analysis of the specimens by SEM, AFM, TEM and EDX, revealing that an amorphous surface layer, which was approximately $30 \mathrm{~nm}$ thick and contained $\mathrm{Ca}, \mathrm{Cr}, \mathrm{P}, \mathrm{Si}, \mathrm{C}$, and $\mathrm{O}$, had newly formed on the steel surface exposed after deformation of the coating. It is presumed that $\mathrm{Ca}^{2+}$ and $\mathrm{HPO}_{4}{ }^{2-}$ were formed by dissolution of the CaO component in $\mathrm{CaSiO}_{3}$ and hydrolysis of $\mathrm{ZnO}_{3}\left(\mathrm{PO}_{4}\right)_{2}$, respectively, and reacted to form an insoluble Ca-phosphoric acid compound which inhibited corrosion of the metal exposed by cracks. [doi:10.2320/matertrans.M2010290]
\end{abstract}

(Received August 31, 2010; Accepted March 18, 2011; Published May 18, 2011)

Keywords: 55\% aluminum-zinc alloy, coated steel sheet, corrosion, inhibitor, chromate, chromate-free, self-healing, microstructure, crosssectional analysis

\section{Introduction}

Maintenance-free building materials with long-term durability are required to overcome corrosion problems due to acid rain caused by air pollution and spray from snowmelting agents and encourage residential and commercial construction in coastal regions, exemplified by waterfront development. Use of 55\% Al-Zn alloy coated steel sheets has greatly increased as a substitute for the conventional hot-dip galvanized steel sheets. The 55\% Al- $\mathrm{Zn}$ alloy coating on these steel sheets has a dendrite structure with an $\alpha$ phase of $\mathrm{Al}$ solid solution and a $\beta$ phase of $\mathrm{Zn}$ solid solution and exhibit excellent corrosion resistance due to the passivation effect of $\mathrm{Al}$ and the sacrificial anticorrosion effect of $\mathrm{Zn}$. ${ }^{1)}$ Horton $^{2)}$ investigated the correlation between the $\mathrm{Al}$ content in hot-dip Zn-Al alloy coated steel sheets and corrosion resistance and found that the corrosion resistance of 55\% Al$\mathrm{Zn}$ alloy coated steel sheets is two to five times higher than that of hot-dip galvanized steel sheets in various environments.

In general, a chromate coating containing organic resin is applied to $55 \% \mathrm{Al}-\mathrm{Zn}$ coated steel sheets to improve corrosion resistance. ${ }^{3,4)}$ Improvement is achieved through the self-healing effect of $\mathrm{Cr}(\mathrm{VI})$ chemical species (hereafter, $\mathrm{Cr}(\mathrm{VI})$ ) and the barrier effect of $\mathrm{Cr}(\mathrm{III})$ chemical species (hereafter, $\mathrm{Cr}(\mathrm{III})$ ), as well as the barrier effect of the organic resin itself. However, as this alloy coating is harder than the zinciferous coatings, severe forming of $55 \% \mathrm{Al}-\mathrm{Zn}$ alloy coated sheets causes surface cracks deep enough to reach the steel substrate. Even assuming a chromate coating containing an organic resin is applied, rust is initiated at the formed area

\footnotetext{
*1 This Paper was Originally Published in Japanese in J. Japan Inst. Metals 73 (2009) 862-869.

${ }^{*}$ Present address: Analysis and Characterization Division, JFE TechnoResearch Corporation
}

and the appearance of the product is markedly degraded. Although use of this sheet had been limited to applications requiring comparatively light forming, demand for applications which require severe forming, such as roofing and siding, is increasingly steadily due to its design properties and functionality.

Previous reports have demonstrated that the self-healing effect which prevents corrosion at coating defects contributes to the corrosion-resistance provided by the chromate coatings $^{5-9)}$ and a correlation exists between the $\mathrm{Cr}(\mathrm{VI})$ content and corrosion resistance. ${ }^{10-12)}$ Theoretically, the post-forming corrosion resistance of $55 \% \mathrm{Al}-\mathrm{Zn}$ coated steel sheets can be improved by increasing the $\mathrm{Cr}(\mathrm{VI})$ content, but there are practical limits to increases in $\mathrm{Cr}(\mathrm{VI})$, as $\mathrm{Cr}(\mathrm{VI})$ is a watersoluble substance that causes unacceptable environmental pollution when eluted, and also causes yellow discoloration of the coating. Thus, a new approach to improving postforming corrosion resistance without using $\mathrm{Cr}(\mathrm{VI})$ had been required. Chromate-free coatings are also needed for steel sheets plated with zinciferous metal, which are widely used in electric appliances, in order to comply with environmental regulations such as the RoHS Directive. It is no exaggeration to say that the search for substances with self-healing effects as substitutes for $\mathrm{Cr}(\mathrm{VI})$ is the most critical issue for the development of chromate-free coatings.

In order to improve the post-forming corrosion resistance of $55 \% \mathrm{Al}-\mathrm{Zn}$ coated steel sheets, the authors carried out an experimental study of the self-healing effect by adding different corrosion inhibitors other than $\mathrm{Cr}(\mathrm{VI})$ to the organic-inorganic composite coating used on this type of sheet. The results showed that extremely high corrosion resistance superior to that of $\mathrm{Cr}(\mathrm{VI})$ can be obtained by adding calcium silicate to zinc phosphate. ${ }^{13,14)}$ The contributions of these two compounds to corrosion resistance were investigated quantitatively, and the mechanism responsible for improvement of post-forming corrosion resistance was 
Table 1 Corrosion-preventive additives used for this work.

\begin{tabular}{cc}
\hline Type & Compounds \\
\hline A & $\mathrm{Zn}_{3}\left(\mathrm{PO}_{4}\right)_{2}$ \\
\hline $\mathrm{B}$ & $\mathrm{Zn}_{3}\left(\mathrm{PO}_{3}\right)_{2}$ \\
\hline $\mathrm{C} 1$ & $88 \mathrm{mass}_{2} \mathrm{Zn}_{3}\left(\mathrm{PO}_{4}\right)_{2}+12 \mathrm{mass}_{\mathrm{CaSiO}} \mathrm{Ca}_{3}$ \\
\hline $\mathrm{P}$ & $\mathrm{PbO}$ \\
\hline $\mathrm{E}$ & $\mathrm{BaCrO}_{4}$ \\
\hline
\end{tabular}

examined by analyzing the composition and structure of the corrosion products on the surface of formed sections after the corrosion test.

\section{Experimental}

\subsection{Corrosion-preventive additives}

The inorganic corrosion-preventive additives used in this study are shown in Table $1 .^{15,16)}$ Zinc phosphate (A), zinc phosphite $(\mathrm{B})$, and a mixture $(\mathrm{C} 1)$ of calcium silicate and zinc phosphate were employed as precipitation-type corrosionpreventive additives. Lead oxide (D) and barium chromate (E) were tested as passivation-type corrosion-preventive additives.

\subsection{Specimens}

Organic-inorganic composite coatings were prepared using a chromate treatment solution to which acrylic resin and phosphoric acid had been added. The basic composition was acrylic resin, $\mathrm{Cr}$, and phosphoric acid in the ratio of $75: 1: 2$ (mass ratio). The corrosion-preventive additives were also added to the acrylic resin in the ratio of 25 or $50: 100$ (mass ratio). $\mathrm{Cr}$ was added as a partially-reduced chromic acid solution, which was prepared by reducing $\mathrm{Cr}(\mathrm{VI})$ to $\mathrm{Cr}(\mathrm{III})$ by adding cane sugar to a chromic acid solution $(20 \mathrm{~g} / \mathrm{l})$ until a $\mathrm{Cr}(\mathrm{III}) /(\mathrm{VI})$ mass ratio of $30 / 70$ was achieved. These solutions were diluted so as to obtain a $\mathrm{Cr}$ coating weight of $20 \mathrm{mg} / \mathrm{m}^{2}$ as metallic Cr. Specimens were prepared by coating the diluted solutions on 55\% Al- $\mathrm{Zn}$ coated steel sheets (sheet thickness: $0.5 \mathrm{~mm}$, zinc coating weight: 75 $\mathrm{g} / \mathrm{m}^{2}$ on one side) with a bar coater, followed by drying (peak metal temperature: $120^{\circ} \mathrm{C}$ ).

The organic-inorganic composite coating containing additives $\mathrm{C} 1$ consisting of a mixture of zinc phosphate and calcium silicate exhibited the highest corrosion resistance in this study. Therefore, with this additive, specimens were prepared using different ratios of zinc phosphate and calcium silicate in order to investigate the contributions of the two compounds. Treatment solutions were also prepared using chromic acetate(III) as the $\mathrm{Cr}$ source in the above basic composition in order to elucidate the corrosion mechanism when the self-healing effect of $\mathrm{Cr}(\mathrm{VI})$ was excluded. Specimens were prepared by coating the solutions on electrogalvanized steel sheets (sheet thickness: $0.5 \mathrm{~mm}$; zinc coating weight: $20 \mathrm{~g} / \mathrm{m}^{2}$ on one side), followed by drying (peak metal temperature: $120^{\circ} \mathrm{C}$ ). Under these preparation conditions, the ratio of corrosion-preventive additives (60\% zinc phosphate $+40 \%$ calcium silicate) to acrylic resin was $25: 100$ (mass ratio).

\subsection{Evaluation of corrosion resistance}

The specimens described above were subjected to 5T bending, in which the specimen was bent $180^{\circ}$ while leaving a gap 5 times the sheet thickness, or scratching of the surface with a cutter reaching the steel substrate, after which the edges were sealed with either black tar epoxy resin or transparent adhesive tape. A salt spray test conforming to JIS Z2371 was performed, and the extent of rust generation was investigated. The corrosion resistance of the $5 \mathrm{~T}$ bent sections was estimated using a rating scale of $0-5$ points corresponding to the area of rust on the ridge, 5 points indicating no rust and 0 points indicating rust covering the entire section. Scores were given using the average rating for two specimens having the same coating composition.

\subsection{Surface and cross-sectional analysis of structure and composition}

An organic-inorganic composite coating containing the corrosion-preventive additives zinc phosphate and calcium silicate, which exhibited the best corrosion resistance in the above-mentioned salt spray test, was prepared on an electrogalvanized steel sheet as described in section 2.2. The specimen was subjected to surface and cross-sectional analysis after the salt spray test. For comparison, a specimen coated with an organic-inorganic composite coating without corrosion-preventive additives was subjected to the same analysis.

\subsubsection{Surface analysis}

In order to assess the extent of damage of $55 \% \mathrm{Al}-\mathrm{Zn}$ alloy coating caused by bend forming, secondary electron (SE) images of the surface of the 5T bent section were taken by FE-SEM (Hitachi S-510). The specimen coated with an organic-inorganic composite coating without corrosion-preventive additives was observed at an accelerating voltage of $25 \mathrm{kV}$ after gold vapor deposition.

For examination of the morphology of the corrosion products, SE images were taken with an in-lens detector (LEO, presently Carl Zeiss LEO1530) at an accelerating voltage of $1 \mathrm{kV}$. No electrically conductive material was evaporated onto the specimen surface. Under these conditions, surface substances such as thin oxide layers could be visualized by the difference in the electrical conductivity of the specimen surface layers. ${ }^{17)}$

The composition of the corrosion products was investigated through in-depth elemental analysis by AES (PHI SAM-660) under conditions of primary electron-beam energy: $3 \mathrm{keV}$, beam current: $10 \mathrm{nA}$ and analysis area: $3 \mu \mathrm{m}$. Sputtering was performed using by an $\mathrm{Ar}^{+}$ion gun with a sputtering rate of $5 \mathrm{~nm} / \mathrm{min}$ for a $\mathrm{SiO}_{2}$ layer.

\subsubsection{Cross-sectional analysis}

Cross-sectional analysis of the composition and structure of the corrosion products were carried out by FE-TEM (FEI CM20FEG) and EDX (EDAX Phoenix). TEM samples were prepared by the microsampling method using an FIB device (Hitachi Hi-Tech FB2000A). ${ }^{18)}$ To prevent damage by the ion beam, the specimens were introduced into the FIB device after carbon coating by vacuum deposition, and a protective carbon layer was further formed on the sampling area by chemical vapor deposition (CVD). TEM samples were cut out using a $\mathrm{Ga}$ ion beam and were removed from the 
specimens after joining to a $\mathrm{W}$ probe by CVD. The samples were then fixed on a Mo grid, again using CVD, and thinned with a $\mathrm{Ga}$ ion beam. TEM observation and EDX analysis were carried out at an accelerating voltage of $200 \mathrm{kV}$.

\section{Results}

\subsection{Evaluation of corrosion resistance}

An SE image of the 5T bent section before the corrosion test is shown in Fig. 1. Numerous cracks of various sizes were observed. The interior of the cracks where the steel sheet was exposed is considered to be the initiation site of corrosion.

The results of an evaluation of the corrosion resistance of the $5 \mathrm{~T}$ bends after a $120 \mathrm{~h}$ salt spray test are shown in Fig. 2. The specimen with the organic-inorganic composite coating with lead oxide (additive D), which was expected to have a passivation effect by $\mathrm{pH}$ control in corrosive environments,

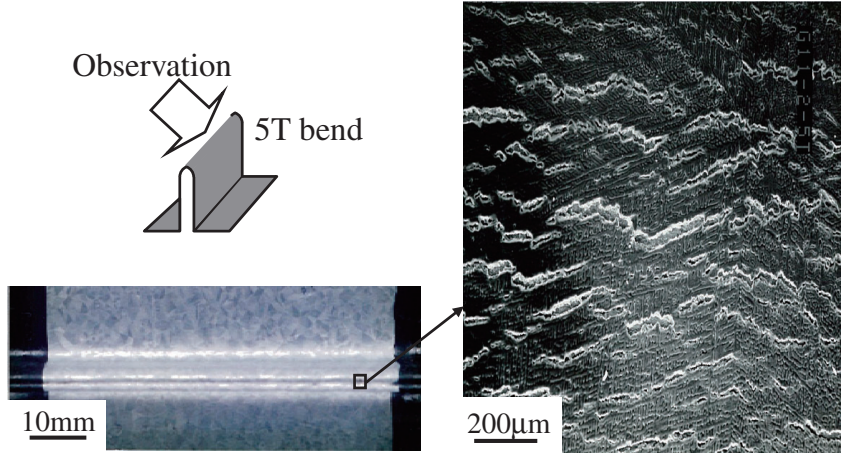

Fig. 1 Appearance and SE image of 5T bent section of 55\% Al-Zn coated steel sheet (Accelerating voltage $=25 \mathrm{kV}$ ). showed lower post-forming corrosion resistance than the specimen without corrosion-preventive additives. However, the specimens with the other corrosion-preventive additives showed improved corrosion resistance. In particular, the post-forming corrosion resistance of the specimen using additives $\mathrm{C} 1$ (zinc phosphate and calcium silicate) was superior to that of the specimen using barium chromate, in which $\mathrm{Cr}(\mathrm{VI})$ was expected to have a passivation effect.

To investigate the relative contributions of zinc phosphate and calcium silicate in additive $\mathrm{C} 1$, which exhibited the best corrosion resistance in the formed specimens, the corrosion resistances of organic-inorganic composite coatings containing various ratios of zinc phosphate and calcium silicate were evaluated in a scratching test. Figure 3 shows the appearances of the specimens after a $240 \mathrm{~h}$ salt spray test. The coatings prepared by mixture of the two compounds (i.e., additives $\mathrm{C} 1-\mathrm{C} 3$ ) suppressed rust generation at the scratched section, and their protective effect increased as the content of the additives increased. In particular, no rust was observed in the scratched section of the specimen using additive $\mathrm{C} 3$, in which the ratio of the corrosion-preventive additives $(33 \%$ zinc phosphate $+67 \%$ calcium silicate) to the acrylic resin was $50: 100$ (mass ratio), indicating the extremely high corrosion resistance of the specimen. Although a greater corrosion resistance effect was seen in the specimen using only zinc phosphate (A) than in the specimen without corrosion-preventive additives, that effect was very small in comparison with the specimens using both zinc phosphate and calcium silicate (C1-C3). In the specimen using only calcium silicate $(\mathrm{C} 4)$, rust was not limited to the scratched section but extended over the whole area; thus, the corrosion resistance with this additive was inferior to that with no corrosion-preventive additive.

\begin{tabular}{|c|c|c|c|c|c|c|c|}
\hline \multirow{2}{*}{\multicolumn{2}{|c|}{$\begin{array}{l}\text { corrosion-preventive } \\
\text { additives }\end{array}$}} & \multirow{2}{*}{$\begin{array}{c}\text { Appearance } \\
\text { of } 5 \mathrm{~T} \text { bent section } \\
10 \mathrm{~mm}\end{array}$} & \multicolumn{5}{|c|}{$\begin{array}{l}\text { Corrosion resistance of } 5 \mathrm{~T} \text { bent section } \\
\text { (Rating after } 120 \mathrm{~h} \text { of salt spray test) }\end{array}$} \\
\hline & & & $\begin{array}{ll}0 & 1\end{array}$ & 2 & 3 & 4 & 5 \\
\hline A & $\mathrm{Zn}_{3}\left(\mathrm{PO}_{4}\right)_{2}$ & & & & & & \\
\hline B & $\mathrm{Zn}_{3}\left(\mathrm{PO}_{3}\right)_{2}$ & (1. & & & & & \\
\hline $\mathrm{C} 1$ & $\mathrm{Zn}_{3}\left(\mathrm{PO}_{4}\right)_{2}+\mathrm{CaSiO}_{3}$ & & & & & & \\
\hline $\mathrm{D}$ & $\mathrm{PbO}$ & $\mathrm{C}-\mathrm{C}$ & & & & & \\
\hline $\mathrm{E}$ & $\mathrm{BaCrO}_{4}$ & & & & & & \\
\hline & Non-additives & 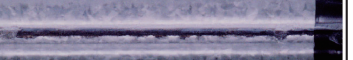 & & & & & \\
\hline
\end{tabular}

Fig. 2 Corrosion resistance of $5 \mathrm{~T}$ bent section of 55\% Al-Zn coated steel sheets with chromate coating containing various corrosionpreventive additives after $120 \mathrm{~h}$ of salt spray test. 


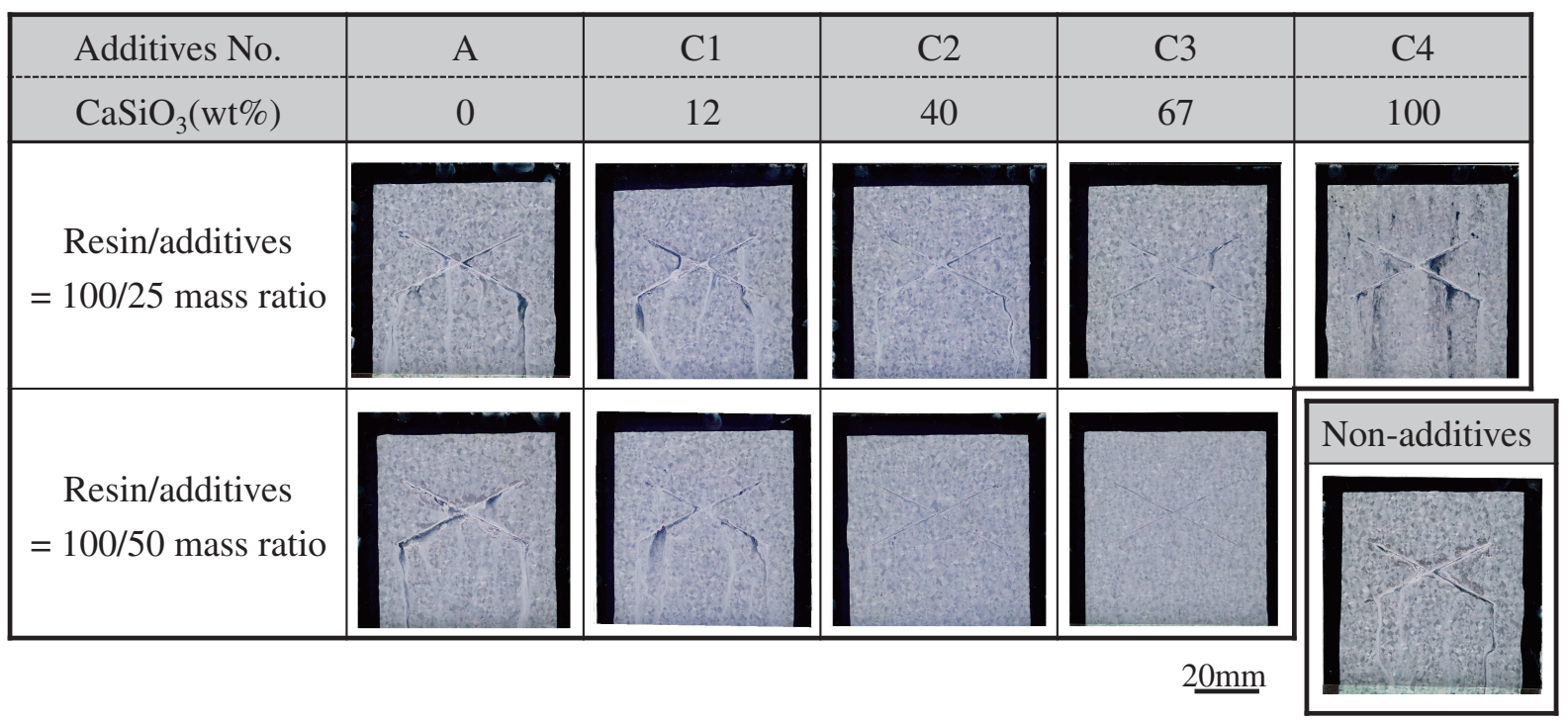

Fig. 3 Appearance of $55 \%$ Al-Zn coated steel sheets with chromate coating containing different ratio of $\mathrm{Zn}_{3}\left(\mathrm{PO}_{4}\right)_{2}$ and $\mathrm{CaSiO}_{3}$ after salt spray test for $240 \mathrm{~h}$.

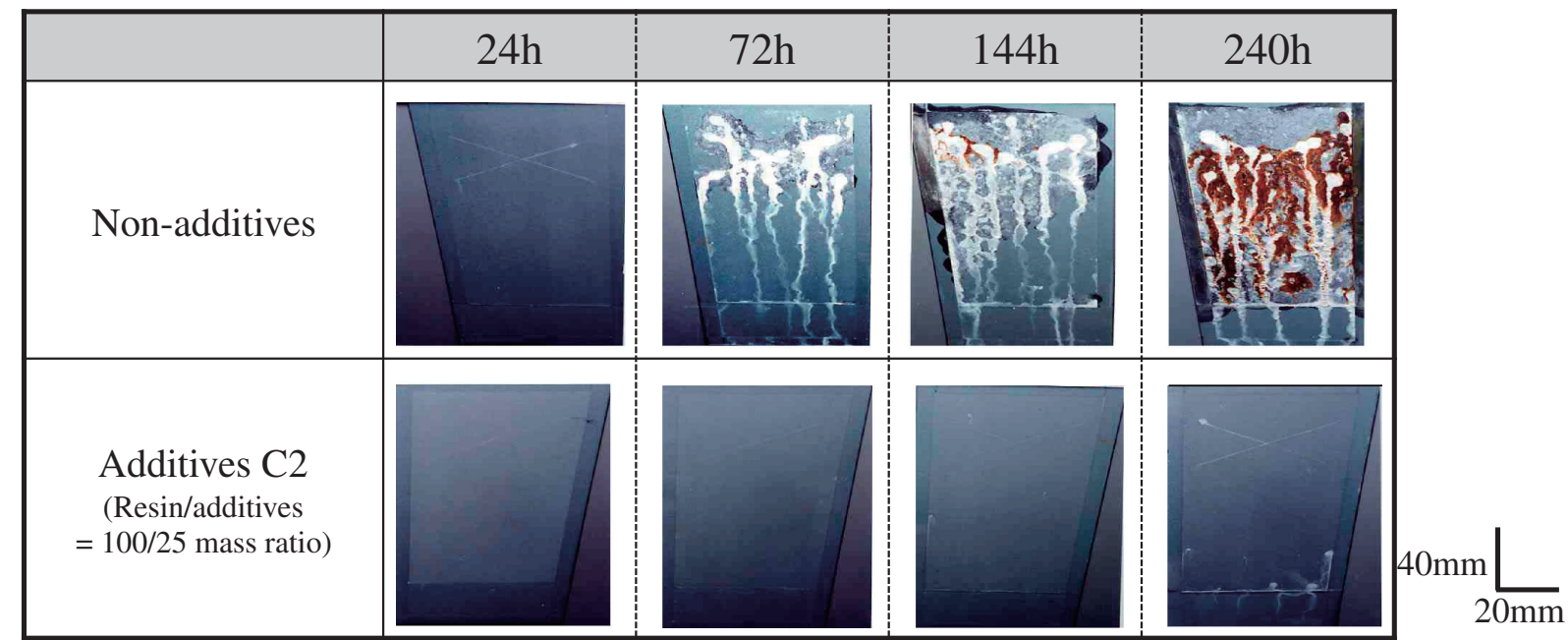

Fig. 4 Appearance of $\mathrm{Zn}$ coated steel sheets with $\mathrm{Cr}(\mathrm{III})$ coating with additives $\mathrm{C} 2$ after salt spray test for various times.

Comparing the results of the scratch test (Fig. 3) and 5T bending test (Fig. 2) with additive $\mathrm{C} 1$ (zinc phosphate and calcium silicate), although the degree of corrosion is larger in the scratch test than in the $5 \mathrm{~T}$ bending test, this difference can be attributed to the fact that exposed steel area is larger and the test time is twice as long in the scratch test. In both corrosion tests, the specimens using additive $\mathrm{C} 1$ displayed higher corrosion resistance than the specimen using only additive A (zinc phosphate). While the size of the defects differs in the two tests, these results suggest that the scratch test is an appropriate method for evaluating corrosion resistance after forming.

In order to elucidate the mechanism responsible for improved post-forming corrosion resistance by a coating containing a mixture of zinc phosphate and calcium silicate, a specimen in which chromic acetate(III) was added as $\mathrm{Cr}$ was prepared on an electrogalvanized steel sheet. A salt spray test was performed using scratched specimens. The appearance of the specimens after the test is shown in
Fig. 4. More severe corrosion was observed in the electrogalvanized steel sheet without corrosion-preventive additives than in the 55\% Al-Zn coated steel sheet (Fig. 3) with $\mathrm{Cr}(\mathrm{VI})$ addition but without the corrosion-preventive additives. That is, the specimen without corrosion-preventive additives showed white rust after $24 \mathrm{~h}$ and red rust after $144 \mathrm{~h}$ at the scratched section. In contrast, the specimen with additive $\mathrm{C} 2$ (zinc phosphate and calcium silicate) retained a metallic gloss on the inside of the scratched section and showed no rust on the scratched section for more than $200 \mathrm{~h}$. Thus, the additives zinc phosphate and calcium silicate also improved the post-forming corrosion resistance of an electrogalvanized steel sheet, although the organic-inorganic composite coating on the sheet included $\mathrm{Cr}(\mathrm{III})$ instead of $\mathrm{Cr}(\mathrm{VI})$. The composition of the electrogalvanized coating is more homogeneous than that of the $55 \% \mathrm{Al}-\mathrm{Zn}$ coating, which comprises a dendrite structure of $\alpha$ phase (Al solid solution) and $\beta$ phase ( $\mathrm{Zn}$ solid solution). This means the corrosion characteristics of electrogalvan- 


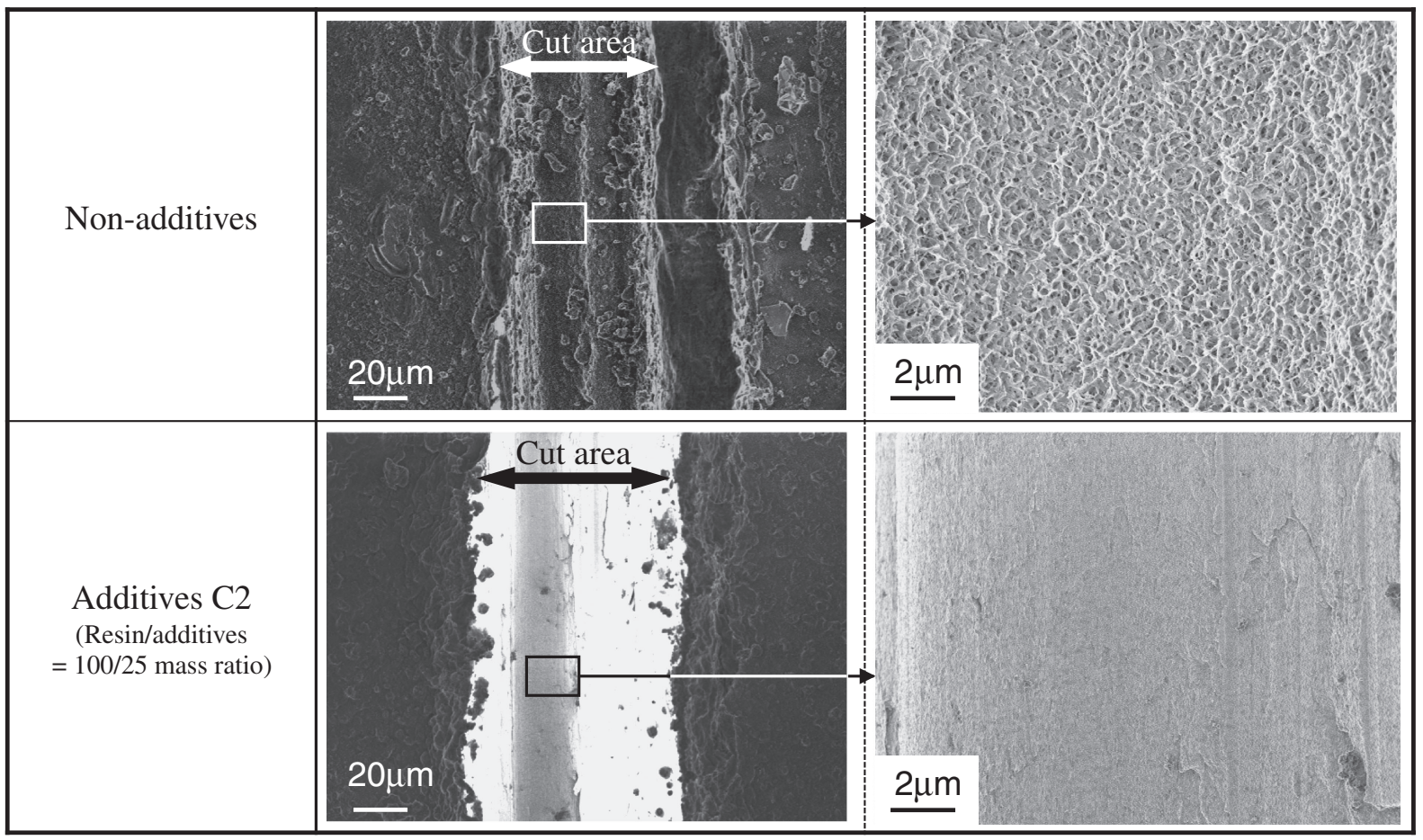

Fig. 5 SE images of scratched section of $\mathrm{Zn}$ coated steel sheets with $\mathrm{Cr}$ (III) coating after salt spray test for $24 \mathrm{~h}$ (Accelerating voltage $=1 \mathrm{kV})$

ized coatings are virtually independent of the observation position. Therefore, in the following, electrogalvanized steel sheets were used as the substrate material for surface and cross-sectional analysis.

\subsection{Surface and cross-sectional analysis \\ 3.2.1 Surface analysis}

Figure 4 showed the specimens of electrogalvanized steel sheets after the salt spray test. After $24 \mathrm{~h}$, specimens were observed by ultra-low accelerating voltage SEM to assess the state of corrosion in the interior of the scratches. SE images of the surfaces of the scratched sections are shown in Fig. 5. In the specimen with additive C2 (zinc phosphate and calcium silicate), the contrast in the scratched section is brighter than that in the specimen without corrosionpreventive additives when observed under low magnification. This suggests that electrification (resulting from accumulation of positive charge due to use of a low accelerating voltage electron beam) is low in this section, that is, surface electroconductivity is high. ${ }^{17)}$ In the image at higher magnification, minute scratch marks are observed in the specimen with the additive $\mathrm{C} 2$. This indicates that the metal is exposed or the corrosion products, assuming they exist, are extremely thin in the scratched section of the specimen with additive $\mathrm{C} 2$. In contrast, since the scratched section of the specimen without the corrosion-preventive additives showed a dark contrast, electroconductivity was considered to be low. In this case, the existence of relatively thick corrosion products with a porous structure on this surface is conceivable. AES depth profiles of the scratched sections of the two specimens are shown in Figs. 6 and 7. In the specimen without corrosion-preventive additives, which showed white rust in Fig. 4, a film comprising mainly $\mathrm{Zn}$ and $\mathrm{O}$ and also
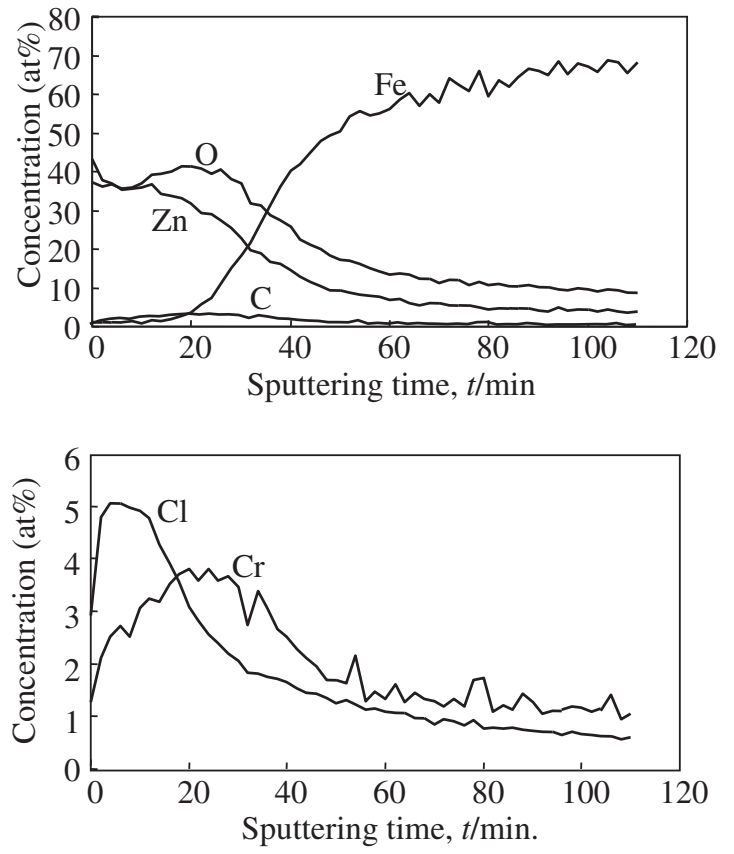

Fig. 6 Depth profiles at the bottom of scratched section of $\mathrm{Zn}$ coated steel sheet with $\mathrm{Cr}$ (III) coating after salt spray test for $24 \mathrm{~h}$.

containing $\mathrm{Cr}$ had formed, and $\mathrm{Cl}$ was concentrated in the outermost layer. A film thickness of approximately $200 \mathrm{~nm}$ was estimated from the sputtering rate of $\mathrm{SiO}_{2}$, assuming the position at which the $\mathrm{O}$ concentration is half that at the surface is the interface between the film/metal substrate. In contrast, the film that formed on the specimen using additive $\mathrm{C} 2$, in which the scratched section retained its metallic gloss after the salt spray test (Fig. 4), comprised mainly $\mathrm{Ca}, \mathrm{C}$ and 
$\mathrm{O}$, and also contained $\mathrm{Si}, \mathrm{P}, \mathrm{Zn}$, and $\mathrm{Cr}$ but no $\mathrm{Cl}$. This film was as thin as approximately $30 \mathrm{~nm}$. Thus, the composition and thickness of the corrosion product layers formed in the scratched section after the salt spray test differed significantly, depending on whether additive C2 was used or not.

\subsubsection{Cross-sectional analysis}

The scratched section of the specimen using additive $\mathrm{C} 2$ after the salt spray test was cut into a slice by the FIB micro-
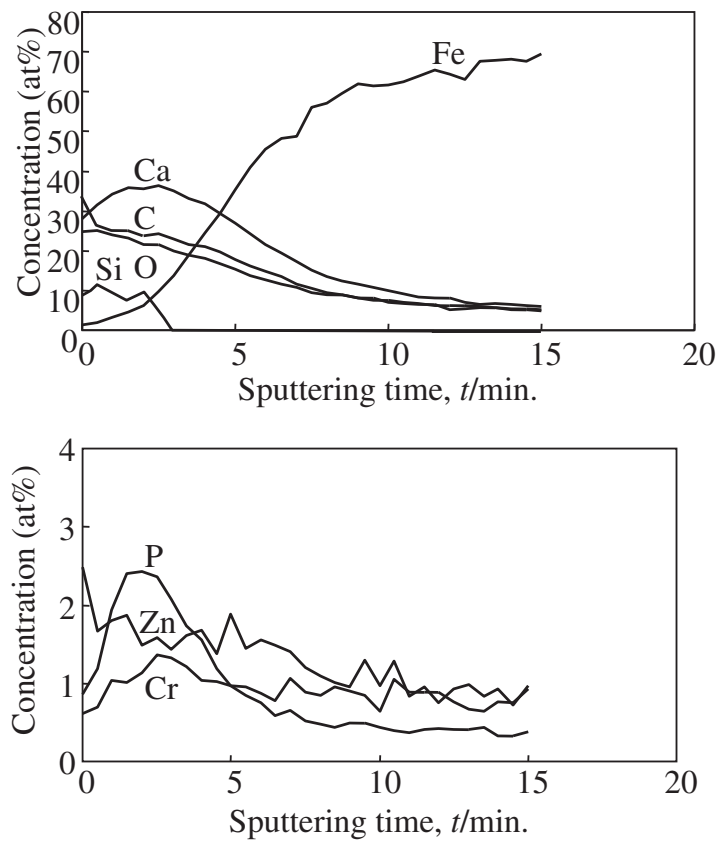

Fig. 7 Depth profiles at the bottom of scratched section of $\mathrm{Zn}$ coated steel sheet with $\mathrm{Cr}(\mathrm{III})$ coating containing additive $\mathrm{C} 2$ after salt spray test for $24 \mathrm{~h}$.

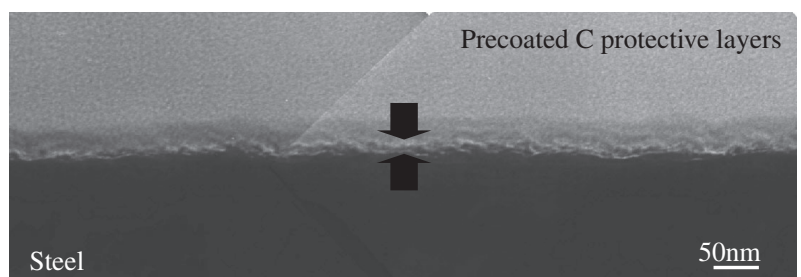

Fig. 8 Cross-sectional TEM image of scratched bottom section of $\mathrm{Zn}$ coated steel sheet with $\mathrm{Cr}(\mathrm{III})$ coating containing additive $\mathrm{C} 2$ after salt spray test for $24 \mathrm{~h}$. sampling method, and cross-sectional microstructural analysis was performed by TEM. A bright field image is shown in Fig. 8, and EDS spectra and electron diffraction patterns are shown in Fig. 9. An amorphous surface layer containing $\mathrm{Ca}$, $\mathrm{Cr}, \mathrm{P}, \mathrm{Si}$, and other elements with a thickness of approximately $30 \mathrm{~nm}$ had formed on the steel surface. These results are consistent with those obtained by SEM and AES. The Ga and Mo components in the EDS spectra are thought to be due to contamination during the FIB micro-sampling, as a Ga ion beam and Mo grid were used.

\section{Discussion}

The corrosion reaction of a metal $\mathrm{M}$ in a neutral aqueous solution is as follows: ${ }^{19)}$

$$
\begin{gathered}
\mathrm{M} \rightarrow \mathrm{M}^{\mathrm{z}+}+\mathrm{ze}^{-} \\
\mathrm{O}_{2}+2 \mathrm{H}_{2} \mathrm{O}+4 \mathrm{e}^{-} \rightarrow 4 \mathrm{OH}^{-}
\end{gathered}
$$

Furthermore, $\mathrm{M}^{\mathrm{z}+}$ and $\mathrm{OH}^{-}$react as follows:

$$
\mathrm{M}^{\mathrm{z}+}+\mathrm{zOH}^{-} \rightarrow \mathrm{M}(\mathrm{OH})_{\mathrm{z}}
$$

According to Meyer ${ }^{19)}$ who investigated the mechanism of corrosion-prevention of iron by zinc phosphate, when zinc phosphate exists in the corrosive environment shown above, the hydrolysis reaction (4) of zinc phosphate occurs due to alkalization by reaction (2):

$$
\mathrm{Zn}_{3}\left(\mathrm{PO}_{4}\right)_{2}+2 \mathrm{H}_{2} \mathrm{O}+4 \mathrm{OH}^{-} \rightarrow 3 \mathrm{Zn}(\mathrm{OH})_{2}+2 \mathrm{HPO}_{4}{ }^{2-}
$$

In other words, the corrosion-preventive action of zinc phosphate is the result of the formation of a protective layer, triggered by the corrosion reaction of the metal.

The effect of adding calcium silicate is considered in terms of its constituent oxides, $\mathrm{SiO}_{2}$ and $\mathrm{CaO} . \mathrm{SiO}_{2}$ is a typical additive in chromate coatings and is widely used as it greatly enhances the corrosion resistance of such coatings. ${ }^{20}$ The corrosion-preventive mechanism of $\mathrm{SiO}_{2}$ has been actively investigated and is thought to be as follows:

(1) Suppression of the oxygen reduction reaction by promoting the formation of basic zinc chloride ${ }^{21)}$

(2) Suppression of the anodic reaction by fixation of $\mathrm{Zn}^{2+}$ ion by the silanol group ${ }^{22)}$

(3) Suppression of the anodic reaction by formation of a $\mathrm{SiO}_{2}$ film ${ }^{23)}$

(4) Barrier effect by formation of silicate zinc ${ }^{24)}$

However, none of these studies explained how $\mathrm{SiO}_{2}$
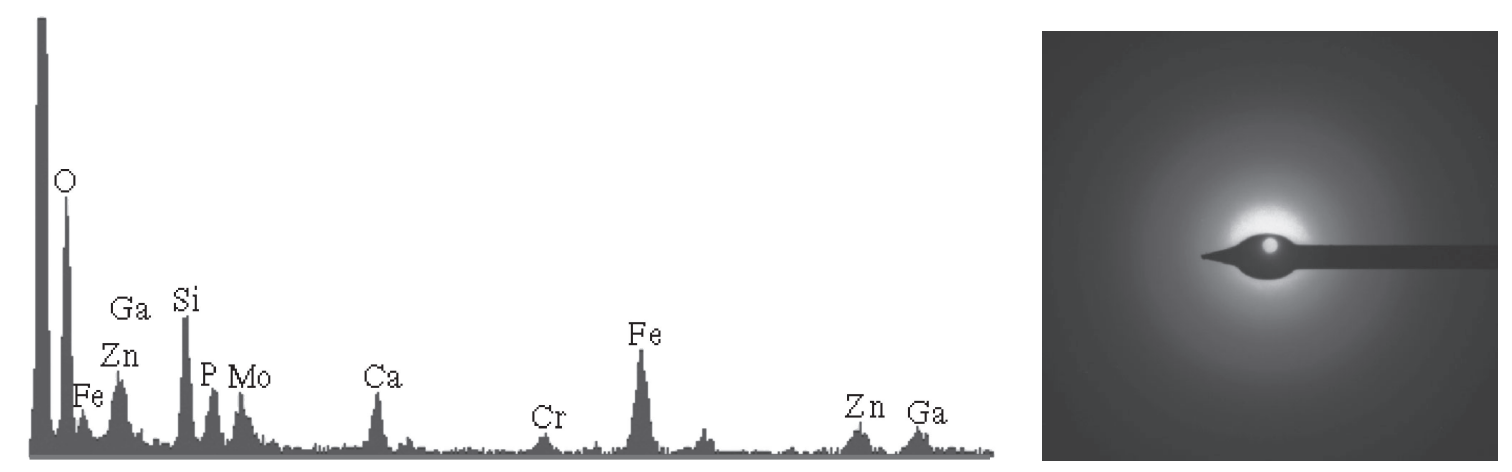

Fig. 9 EDS spectra and electron diffraction patterns of newly formed thin film on scratched bottom section after salt spray test for $24 \mathrm{~h}$. 
improves post-forming corrosion resistance. Moreover, as the dissolution reaction of $\mathrm{Zn}$ is involved in all of the mechanisms mentioned above, $\mathrm{SiO}_{2}$ cannot be considered the primary factor in improving post-forming corrosion resistance.

$\mathrm{CaO}$ forms $\mathrm{Ca}(\mathrm{OH})_{2}$ in aqueous solutions by the following reactions:

$$
\begin{aligned}
& \mathrm{CaO}+\mathrm{H}_{2} \mathrm{O} \rightarrow \mathrm{Ca}(\mathrm{OH})_{2} \\
& \mathrm{Ca}(\mathrm{OH})_{2} \rightarrow \mathrm{Ca}^{2+}+2 \mathrm{OH}^{-}
\end{aligned}
$$

Since the solubility of $\mathrm{Ca}(\mathrm{OH})_{2}$ is $0.097 \mathrm{~g} / 100 \mathrm{~g}\left(0^{\circ} \mathrm{C}\right),{ }^{25)} \mathrm{pH}$ will increase to 12.4 if $100 \%$ of the dissolved $\mathrm{Ca}(\mathrm{OH})_{2}$ is ionized. The dissolution rates of $\mathrm{Zn}$ and $\mathrm{Al}$ increase when the solution $\mathrm{pH}$ is higher than approximately $12-13^{26)}$ and $11,{ }^{27)}$ respectively. Therefore, it is thought that the specimen using only calcium silicate was dissolved as a result of the high alkalization of the specimen surface by dissolution of the $\mathrm{CaO}$ component, and for this reason, its corrosion resistance was lower than that of the specimen without the corrosion-preventive additives (Fig. 3).

In the case of the specimen with the additives zinc phosphate and calcium silicate, reaction (6) is thought to promote the hydrolysis reaction (4), and the $\mathrm{HPO}_{4}{ }^{2-}$ and $\mathrm{Ca}^{2+}$ which are formed by reactions (4) and (6), respectively, react to form a Ca-phosphoric acid compound. This Ca-phosphoric acid compound forms various structures, depending on the ratio of $\mathrm{Ca}$ and phosphoric acid. Insoluble compounds such as hydroxyapatite $\mathrm{Ca}_{10}\left(\mathrm{PO}_{4}\right)_{6}(\mathrm{OH})_{2}$ are formed when the $\mathrm{Ca}$ ratio is high. ${ }^{28)}$ As a result, a dense, extremely thin layer consisting of an insoluble Ca-phosphoric acid compound is thought to have formed, and this substance inhibited the corrosion reaction of the exposed part of steel sheet under the corrosive environment. A large amount of $\mathrm{C}$ detected by AES analysis in Fig. 7 is considered to derive from $\mathrm{CaCO}_{3}$, which may be formed by reaction of the $\mathrm{Ca}^{2+}$, which remained after corrosion was arrested by the formation of the above-mentioned insoluble Ca-phosphoric compound, with $\mathrm{CO}_{2}$ dissolved from the air. The specimen without corrosion-preventive additives was covered with a thick layer of corrosion products consisting mainly of $\mathrm{Zn}$ and $\mathrm{O}$, and it can be presumed that this layer is less protective against corrosion due to its porous structure. It should be noted that this discussion is based on surface and cross-sectional analysis of specimens using an electrogalvanized steel sheet substrate. In the future, it will be necessary to investigate the mechanism by which post-forming corrosion resistance is improved with $55 \% \mathrm{Al}-\mathrm{Zn}$ coated steel sheets, while also considering the contribution of the sacrificial anodic action of the plating.

\section{Conclusion}

With the aim of improving the post-forming corrosion resistance of $55 \% \mathrm{Al}-\mathrm{Zn}$ coated steel sheets, the authors attempted to induce a self-healing effect by adding corrosion inhibitors other than $\mathrm{Cr}(\mathrm{VI})$ to the organic-inorganic composite coating formed on the sheet using a chromate solution containing acrylic resin, phosphoric acid additives, and other chemical compounds. Inorganic compounds with various corrosion-preventive actions were added to the coating, and post-forming corrosion resistance was investigated. The mechanism responsible for improved post-forming corrosion resistance was investigated with specimens using an additive consisting of a mixture of zinc phosphate and calcium silicate, which exhibited extremely high corrosion resistance. The following results were obtained.

(1) The $55 \% \mathrm{Al}-\mathrm{Zn}$ coated steel sheets on which an organic-inorganic composite coating containing zinc phosphate and calcium silicate was formed exhibited an extremely high corrosion inhibition effect in the salt spray test, surpassing that provided by $\mathrm{Cr}(\mathrm{VI})$. The effect was very small with the specimen using only a zinc phosphate additive, and the corrosion resistance of the specimen using only calcium silicate was lower than that with no corrosion-preventive additives.

(2) Use of the zinc phosphate and calcium silicate additive also resulted in extremely high post-forming corrosion resistance of electrogalvanized steel sheets with an organic-inorganic composite coating containing chromic acetate(III) as $\mathrm{Cr}$, which was studied in order to exclude the self-healing effect of $\mathrm{Cr}(\mathrm{VI})$. An amorphous surface layer, which was approximately $30 \mathrm{~nm}$ thick and contained $\mathrm{Ca}, \mathrm{Cr}, \mathrm{P}$, and $\mathrm{Si}$, newly formed on the interior of the formed section where the steel sheet was exposed.

(3) When $\mathrm{CaO}$ in calcium silicate comes into contact with water, it forms $\mathrm{Ca}(\mathrm{OH})_{2}$ creating an alkaline environment on the steel sheet by forming $\mathrm{Ca}^{2+}$ and $\mathrm{OH}^{-}$ which promotes the hydrolysis reaction of zinc phosphate. It is thought that an insoluble Ca-phosphoric acid compound was formed by reaction of the $\mathrm{Ca}^{2+}$ and $\mathrm{HPO}_{4}{ }^{2-}$ resulting from these reactions, and this compound inhibited the corrosion reaction.

\section{REFERENCES}

1) C. Kato and K. Yoshida: Kinzoku 74 (2004) 559-565.

2) J. B. Horton: Meet. Corros. Control Coat. 1978 (1979) 59-73.

3) A. Matsuzaki, T. Yamaji and M. Yamashita: Proc. 5th Int. Conf. on Zinc and Zinc Alloy Coated Steel Sheet (GALVATECH'2001), (CRM, Brussels, 2001) pp. 663-669.

4) A. Matsuzaki, T. Yamaji, K. Yoshida and M. Yamashita: Tetsu-toHagané 89 (2003) 123.

5) A. Gallaccio, F. Pearlstein and M. R. D'ambrosio: Met. Finish. 64 (1966) 50-54.

6) R. J. Sunderland: Proc. 6th Int. Vac. Cong., (1974) pp. 347-350.

7) A. Suda, T. Shinohara, S. Tsujikawa, T. Ogino and S. Tanaka: Zairyoto-Kankyo 41 (1992) 244-245.

8) A. Suda, T. Shinohara, S. Tsujikawa, T. Ogino and S. Tanaka: Proc. 2nd Int. Conf. on Zinc and Zinc Alloy Coated Steel Sheet (GALVATECH'1992), (CRM, Amsterdam, 1992) pp. 250-254.

9) A. Suda and M. Asari: Zairyo-to-Kankyo 46 (1997) 95-102.

10) H. L. Katz, K. L. Proctor and F. Nagley: Proc. Am. Soc. Test. Mater. 57 (1957) pp. 203-218.

11) T. Biestek: Galvanotechnik 63 (1972) 303-314.

12) L. H. Esmore and B. D. Lindenmayer: Electroplat. Met. Finish. 26 (1973) 18-19.

13) T. Yamaji, A. Matsuzaki, M. Yamashita, Y. Majima and H. Ishikawa: Materia Japan 42 (2003) 73-75.

14) A. Matsuzaki, T. Yamaji and M. Yamashita: Surf. Coat. Technol. 169/170 (2003) 655-657.

15) I. Matsushima: Denki Kagaku 54 (1986) 378. 
16) K. Aramaki: Bosei Kanri 41 (1997) 407.

17) M. Nagoshi, T. Kawano and K. Sato: J. Surf. Finish. Soc. Jpn. 54 (2003) 31-34.

18) H. Noro, K. Okai, A. Matsuzaki and N. Yoshimi: Proc. 7th Int. Conf. on Zinc and Zinc Alloy Coated Steel Sheet (GALVATECH'2007), (ISIJ, Osaka, 2007) pp. 757-761.

19) G. Meyer: Schweiz. Arch. Angew. Wiss. Tech. 31 (1965) 52-56.

20) M. Nakazawa and M. Yoneno: Tetsu-to-Hagané 77 (1991) 115122

21) T. Kubota and M. Yamashita: Tetsu-to-Hagané 81 (1995) 76-81.

22) K. Takao, T. Honzyo, Y. Yamato and N. Morito: CAMP-ISIJ 4 (1991) p. 1664.
23) S. Miyauchi, H. Ido, K. Ikeda, T. Nakamoto, T. Kajita and M. Imahori: Tetsu-to-Hagané 89 (2003) 116-122.

24) S. Sujita, K. Mochizuki and N. Morito: Tetsu-to-Hagané 84 (1998) 777-784.

25) Chemical References Primary Book II Revised 2nd ed., ed. by The Chemical Society of Japan, (Maruzen, Tokyo, 1975) p. 779.

26) M. Pourbaix: Atlas of electrochemical equilibria 2nd edition, National Association of Corrosion Engineers, (Houston, 1974) p. 173.

27) M. Pourbaix: Atlas of electrochemical equilibria 2 nd edition, National Association of Corrosion Engineers, (Houston, 1974) p. 410.

$28)$ E. Kobayashi: Extra Number of Kagaku Kogyou, Chemistry and Use of Phosphoric Salt, (Kagaku Kougyou-sha, Tokyo, 1967) p. 130. 